\title{
Evaluasi Hasil Produksi Dengan Metode Pengendali Mutu C-Chart Dan $U$-Chart Di Pabrik Generator Sets PT ABC
}

\author{
Daniel Tunggono Saputro ${ }^{1)}$, Kustanto $^{2)}$ \\ ${ }^{1}$ Program Studi Teknik Informatika Universitas AKI Semarang, ${ }^{2}$ Program Studi Teknik Informatika \\ STMIK Sinar Nusantara Surakarta, \\ 11daniel.tunggono@unaki.ac.id, ${ }^{2}$ kustanto@sinus.ac.id
}

\begin{abstract}
Abstrak
Perusahaan Generator Sets (Genset) PT ABC yang didirikan beberapa tahun lalu telah memproduksi genset yang sudah cukup banyak. Dengan kapasitas produksi sekitar 1000 pcs genset setiap tahunnya, maka diperlukan analisa dan evaluasi terhadap hasil produksi gensetnya. Diperlukan sebuah Tindakan agar perusahan semakin maju dan berkembang agar dapat terus berkompetisi di dunia usaha bisnis genset. Hasil produksi genset yang siap dijual harus mempunyai kualitas yang baik dan reliable (tahan lama). Dikarenakan komponen genset yang cukup banyak sehingga dalam memproduksi genset harus memerlukan keahlihan dan ketelitian yang baik sehingga hasil produksi genset tidak mengalami cacat produksi. Cacat dalam pengelasan, cacat dalam merangkai kabel, dlldapat terjadi dalam memproduksi genset. Digunakan metode pengendali mutu $C$-chart dan $U$-chart dalam mengevaluasi hasil produksi yang dihasilkan. Dengan kedua metode tersebut dapat terlihat apakah hasil produksi masih dalam batas yang terkendali atau sudah di luar batas kendali.
\end{abstract}

Kata kunci:pengendali mutu, $c$-chart, $u$-chart, produksi

\begin{abstract}
Abtract
PT ABC Generator Sets (Genset) company which was founded several years ago has produced quite a lot of generators. With a production capacity of about 1000 pes of generators per year, it is necessary to analysis and evaluate the results of the production of the generator. Action is needed so that the company is progressing and developing in order to continue to compete in the generator business world. The production of a generator that is ready for sale must be of good quality and reliable (durable). Due to the many components of the generator set so that in producing a generator, it must require good skill and accuracy so that the production of the generator does not experience production defects. Defects in welding, defects in stringing cables, etc. can occur in producing generator sets. The C-chart and U-chart quality control methods are used in evaluating the resulting production results. With these two methods, it can be seen whether the production results are still within controlled limits or out of control.
\end{abstract}

Keywords: quality control, c-chart, u-chart, production

\section{PENDAHULUAN}

PT ABC merupakan sebuah perusahaan yang bergerak di bidang manufaktur memproduksi genset. Dalam memproduksi genset ini dapat dikatakan sebagai kegiatan merakit komponen - komponen sehingga menjadi sebuah barang jadi yaitu Generator sets (Genset). Komponen - komponen ini ada yang diproduksi di dalam pabrik atau ada yang dibeli pasar dalam negeri dan luar negeri / ekspor.
Dengan banyaknya komponen yang harus diproduksi dan dirakit, maka tentunya semakin banyak kemungkinan cacat produksi yang akan terjadi di setiap produk genset. Tentunya hal ini tidak boleh terjadi di produksi genset, hasil produksi genset harus merupakan genset yang siap pakai tanpa cacat produksi. Tetapi kejadian adanya cacat produksi / kerusakan dari hasil produksi akan selalu terjadi. Jika ada kerusakan ditemukan pada saat pengecekan di bagian Quality Control (QC) maka akan dilakukan proses 
pengembalian ke bagian-bagian terkait untuk dilakukan perbaikan. Terntunya hal ini akan membuat proses tidak efeisien dan efektif sehingga dapat menimbulkan pemborosan. Oleh karena itu perusahaan ini mengadakan analisa dan evaluasi mengenai hasil produksi yang dihasilkan masih merupakan hasil yang wajar (batas kendali) atau diluar batas kendali. Jika hasil yang dihasilkan diluar batas kendali, maka dapat dilakukan evaluasi lebih lanjut misalnya dengan pemberian kursus bagi tenaga kerja atau penggantian tenaga kerja.

Dengan melakukan analisa dan evaluasi dari jumlah kerusakan / ketidaksesuaian kriteria yang terjadi pada sebuah / di setiap hasil produksi maka hal ini adalah salah satu cara untuk mendapatkan sebuah produks yang baik dan handal sehingga produks tersebut dapat menjadi produks kepercayaan konsumen. Dan Perusahaan dapat berkompetisi dengan baik.

Tujuan dari analisa dan evaluasi ini adalah agar didapatkan sebuah data / hasil yang bertujuan untuk melakukan evaluasi bagian produksi. Apakah tenaga kerja sudah bekerja dengan baik dan benar dan produksi dapat dikendalikan? Jika belum maka diperlukan untuk melakukan evaluasi terhadap tenaga kerja yang ada. Produk yang terjadi kecacatan harus dilakukan perbaikan atau di lakukan produksi kembali sehingga hal ini akan menimbulkan pemborosan waktu, biaya dan tenaga.

Penulisan ini hanya membatasi mengenai analisa banyaknya kerusakan / cacat yang terjadi pada setiap produksi genset. Semua hasil produksi genset akan dilakukan observasi dan dimasukkan datanya kemudian diolah dengan metode peta kendali $C$-chart dan U-chart.

Penggunaan peta kendali $U$-chart telah digunakan dalam penelitian untuk meneliti kerusakan yang terjadi pada setiap hasil produksi kemasan botol sosro di PT X Suarabaya, sehingga dihasilkan dapat digunakan sebagai analisa produksi (Yemima, Ola 2014)

\section{METODE PENELITIAN}

Metode penelitian menggunakan metode studi literatur tentang pengendali mutu, observasi wawancara bagian Produksi dan bagian Quality Control Pabrik Genset PT ABC. Pengelompokkan dan mencari penyebab cacat produksi, kemudian mengumpulkan data kerusakan / cacat produksi kemudian datanya tersebut dapat dilakukan penghitungan dengan Microsot Excel dan Minitab

\section{TINJAUAN PUSTAKA}

a. Definisi Mutu (Kualitas)

Definisi mutu atau kualitas mempunyai banyak definisi, diantaranya adalah:

1) Menurut Juran dan Gryna adalah fitness for use (kepuasan guna). Bagi konsumen mutu berarti kemudahan dalam memperoleh barang, keamanan, kenyamanan dalam mempergunakan dan dapat memenuhi keinginan. (Juran and Gyrna, 1980: 1-2).

2) Menurut Garvin, mutu adalah suatu kondisi dinamis yang berhubungan dengan produk, manusia / tenaga kerja, proses dan tugas, serta lingkungan yang memenuhi atau melebihi harapan pelanggan atau konsumen.

3) Menurut Gasperz adalah segala sesuatu yang dapat memenuhi keinginan atau kebutuhan pelanggan. (Gasperz, 2006).

4) Menurtut Edwar Deming, mutu adalah kesesuaian dengan kebutuhan pasar. Menurut Deming (Schuler dan Harris, 1992:23) bahwa produk atau layanan bermutu tinggi jika pelanggan menganggap produk yang dibelinya memiliki nilai baik, setia sebagai pelanggan, dan mengajak yang lain untuk membeli produk atau layanan tersebut.

Jadi mutu merupakan sesuatu yang menjadi keinginan, kepuasaan bagi pelanggan atau konsumen dan bilamana pelanggan mengganggap produk tersebut baik, maka akan mengajak orang lain untuk membeli / memiliki barang tersebut.

\section{b. Definisi Pengendali Mutu (Quality Control)}

Pengendali mutu (Quality Control) kegiatan yang terpadu dan saling berkaitan yang dimulai dari pengendalian mutu bahan, standar proses produksi dari awal sampai akhir dan pengiriman agar barang yang dihasilkan dapat memenuhi keinginan dan kepuasan konsumen. Gasperz (2014) mengemukakan bahwa tujuan pengendalian kualitas antara lain hasil produksi sesuai 
dengan spesifikasi yang ditetapkan, agar dapat menekan biaya kualitas seminimal mungkin.

\section{c. Peta Kendali $\boldsymbol{C}$-Chart}

Huruf $\mathrm{C}$ pada $C$-chart artinya adalah "count" atau hitung cacat, yang berarti bahwa $C$-chart dibuat berdasarkan pada banyaknya cacat dalam suatu item.

Sebuah.produk dikatakan cacat (defective) adalah produk yang beberapa kreteria / beberapa hal gagal memenuhi satu atau lebih spesifikasi yang ditetapkan. Setiap kekurangan disebut dengan defec. Setiap produk yang cacat biasa saja terdapat lebih dari satu defec (yang harus diperhatikan adalah banyaknya defec). Secara umum dalam peta kendali C-chart yang diperhatikan adalah mengenai banyaknya cacat atau cacat per tiap unit obyek atau barang.

Peta pengendali ini digunakan untuk mengadakan pengujian terhadap kualitas proses produksi dengan mengetahui banyaknya kesalahan pada satu unit produk sebagai sampelnya dan sample yang terjadi dianggap tetap / konstan.

Langkah - langkah dalam pembuatan peta kendali $C$-chart:

1. Mengumpulkan banyaknya sampel (n)

2. Menghitung garis pusat (Center Line)

$$
C L=\overline{\mathrm{C}}=\frac{\sum_{i=1}^{n} c i}{n}
$$

$\mathrm{CL}=\overline{\mathrm{C}}=$ Central limit $=$ garis pusat

$\mathrm{Ci}=$ banyaknya produk yang cacat pada setiap observasi

$\mathrm{n}=$ banyak observasi

3. Menghitung batas pengendali bawah (Lower Control Unit)

$$
\begin{gathered}
\mathrm{LCL}=\mathrm{BPB}=\overline{\mathrm{C}}-3 \sqrt{\overline{\mathrm{C}}} \\
\mathrm{LCL}=\text { Lower Control Limit }=\text { Batas } \\
\text { Pengendali Bawah }
\end{gathered}
$$

4. Menghitung batas pengendali atas (Upper Control Unit)

$$
\begin{gathered}
U C L=B P A=\overline{\mathrm{C}}+3 \sqrt{\overline{\mathrm{C}}} \\
\mathrm{UCL}=\begin{array}{c}
\text { Upper Control Limit }=\text { Batas } \\
\text { Pengendali Atas }
\end{array}
\end{gathered}
$$

\section{d. Peta kendali $\boldsymbol{U}$-Chart}

Huruf U dalam $U$-chart artinya adalah "unit" yang berarti cacat dalam kelompok sampel. U-chart menghitung titik cacat per unit laporan pemeriksaan dalam periode yang mungkin memiliki ukuran sampel bervariasi (banyak item yang diperiksa). Jika $C$-chart menghitung titik cacat dalam satu item yang sama, maka $U$-chart digunakan dalam kasus di mana sampel yang diambil bervariasi atau memang seluruh produk yang dihasilkan akan diuji. Hal ini berarti bahwa $U$-chart digunakan jika ukuran sampel lebih dari satu unit atau mungkin bervariasi dari waktu ke waktu. Peta kenali $U$-chart, diperlukan mencari perhitungan $\mathbf{U}$ cacat pada setiap $\mathbf{N}$ sampel.

Langkah - langkah dalam pembuatan peta kendali $U$-chart:

1. Mencari $\mathbf{U}$ pada setiap $\mathrm{N}$ sampel

$$
u i=\frac{x i}{n i}
$$

2. Menghitung garis pusat (Center Line)

$$
C L=\bar{U}=\frac{\sum_{i=1}^{n} c i}{m n}
$$

$$
\begin{aligned}
& \mathrm{CL}=\overline{\mathrm{C}}=\text { Central limit }=\text { garis pusat } \\
& \mathrm{Ci}=\text { banyaknya produk yang cacat pada } \\
& \text { setiap observasi } \\
& \mathrm{n}=\text { banyak observasi } \\
& \mathrm{m}=\text { ukuran sampel }
\end{aligned}
$$

3. Menghitung batas pengendali bawah (Lower Control Unit)

$$
L C L=B P B=\bar{U}-3 \sqrt{\frac{\bar{u}}{n}}
$$

$\mathrm{LCL}=$ Lower Control Limit $=$ Batas Pengendali Bawah

4. Menghitung batas pengendali atas (Upper Control Unit)

$$
U C L=B P A=\bar{U}+3 \sqrt{\frac{\bar{u}}{n}}
$$

$\mathrm{UCL}=$ Upper Control Limit =Batas Pengendali Atas 


\section{e. Generator Sets (genset)}

Generator Sets (genset) adalah sebuah alat yang biasanya digunakan untuk cadangan ketika listrik dari PLN mengalami gangguan. Maka biasanya menggunakaan genset untuk mengganti sumber daya. Penggunaan genset banyak digunakan di rumah sakit, pusat perbelanjaan, dan juga beberapa rumah.

Prinsip kerja genset adalah mengubah energi gerak (kinetik) menjadi energi listrik. Mesin yang ada digenset sebagai energi gerak kan bergerak didalam dynamo (altenator / generator) sehingga menghasilkan listrik.

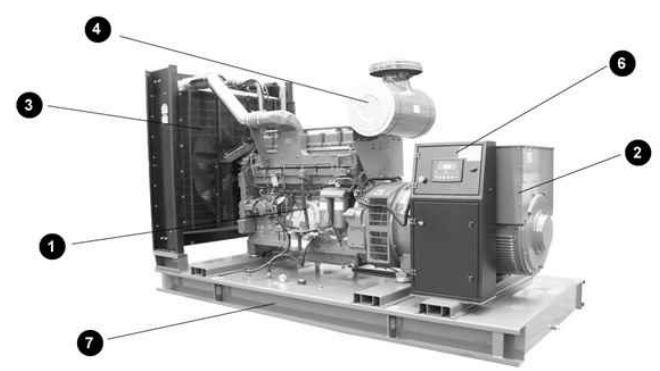

Gambar 1. Genset dan komponennya

Seperti pada gambar 1, komponen genset mempunyai beberapa komponen, antara lain:

1. Mesin, komponen utama yang akan mengubah energi panas menjadi mekanik.

2. Generator adalah bagian dari genset yang berfungsi mengubah energi gerak (kinetik) yang dihasilkan mesin menjadi energi listrik.

3. Radiator adalah bagian dari genset yang berfungsi sebagai sistem pendinginan.

4. Filter udara, yang berfungsi mengatur udara yang akan masuk ke genset

5. Panel, merupakan bagian genset yang berfungsi sebagai pengatur elektrik dari genset

6. Baseframe atau pondasi genset adalah tempat berdirinya genset.

Masih terdapat komponen atau bagian lainnya yang ada di dalam genset tersebut seperti sistem pendinginan, sistem pengaturan udara, sistem pengaturan bahan bakar, dll

Jadi dalam memproduksi bagian genset harus memiliki keahlian - keahlian khusus di setiap bagian untuk menghasilkan sebuah produk genset. Dengan adanya banyaknya bagian yang harus dirakit maka dimungkinkan akan terjadi bagian -bagian yang tidak sesuai dengat spesifikasi yang ditetapkan (cacat).

\section{f. Program Minitab}

Perangkat lunak Minitab adalah salah satu perangkat lunak untuk aplikasi statistika yang banyak digunakan untuk mempermudah pengolahan data statistik. Keunggulan perangkat lunak Minitab adalah dapat digunakan dalam pengolahan data statistika untuk tujuan sosial dan teknik.

\section{HASIL DAN PEMBAHASAN}

Dari data observasi wawancara yang dilakukan terhdapan bagian produksi dan Quality Control maka didapatkan penggolongan kerusakan seperti pada tabel 1 .

Tabel 1. Faktor / penyebab cacat produksi genset

\begin{tabular}{|c|c|c|}
\hline No & $\begin{array}{l}\text { Faktor/ } \\
\text { penyebab } \\
\text { kerusakan }\end{array}$ & Penjelasan \\
\hline 1. & $\begin{array}{l}\text { Kinerja } \\
\text { (Perfomance) }\end{array}$ & $\begin{array}{l}\text { Kinerja genset diukur } \\
\text { dari hasil listrik } \\
\text { (output) yang } \\
\text { dihasilkan oleh genset. } \\
\text { Genset } 7 \mathrm{KW} \text { artinya } \\
\text { genset tersebut akan } \\
\text { mengeluatkan daya } \\
\text { listrik } 7000 \text { watt. }\end{array}$ \\
\hline 2 & $\begin{array}{l}\text { Estetika } \\
\text { (Aesthetic) }\end{array}$ & $\begin{array}{l}\text { Tampilan genset harus } \\
\text { menarik dan baik. } \\
\text { Penentuan baseframe } \\
\text { (pondasi), kerapian las } \\
\text { dan pengecatan akan } \\
\text { membuat genset } \\
\text { terlihat bagus. Bagian } \\
\text { - bagian yang di las } \\
\text { dan dilakukan } \\
\text { pengecatan harus } \\
\text { diamati dengan baik }\end{array}$ \\
\hline 3 & $\begin{array}{l}\text { Ketahanan } \\
\text { (Realibility) }\end{array}$ & $\begin{array}{l}\text { Dilakukan pengetesan } \\
\text { genset } \quad \text { minilmal } \\
\text { selama } 2 \text { jam dan } \\
\text { diawasi parameter - } \\
\text { pamaternya agak tidak } \\
\text { ada yang rusak. }\end{array}$ \\
\hline 4 & Eletrikal & $\begin{array}{l}\text { Pengecekan } \\
\text { sambungan- } \\
\text { sambungan kabel dan } \\
\text { keamanannya }\end{array}$ \\
\hline 5 & Getaran & \begin{tabular}{ll} 
Terjadi & \multicolumn{2}{c}{ getaran } \\
fibrasi yang diluar \\
kriteria
\end{tabular} \\
\hline
\end{tabular}


Perusahaan genset PT ABC mengelompokkan menjadi 3 kategori produksi genset berdasarkan hasil listrik yang dikeluarkan (output yang dihasilkan), yaitu small engine, medium engine dan big engine.

Tabel 2. Tipe genset perusahaan genset PT $\mathrm{ABC}$

\begin{tabular}{|c|c|c|}
\hline Kategori & Tipe & Rating / output \\
\hline Small & $\mathrm{ABC} 3000 \mathrm{SE}$ & $3000 \mathrm{KW}$ \\
\cline { 2 - 3 } Enginne & $\mathrm{ABC} 5000 \mathrm{SE}$ & $5000 \mathrm{KW}$ \\
\cline { 2 - 3 } & $\mathrm{ABC} 7500 \mathrm{SE}$ & $75000 \mathrm{KW}$ \\
\cline { 2 - 3 } & $\mathrm{ABC} 10000 \mathrm{SE}$ & $10.000 \mathrm{KW}$ \\
\cline { 2 - 3 } & $\mathrm{ABC} 15000 \mathrm{SE}$ & $15.000 \mathrm{KW}$ \\
\cline { 2 - 3 } & $\mathrm{ABC} 20000 \mathrm{SE}$ & $20.000 \mathrm{KW}$ \\
\hline Medium & $\mathrm{ABC} 25000 \mathrm{ME}$ & $25.000 \mathrm{KW}$ \\
\cline { 2 - 3 } Engine & $\mathrm{ABC} 30000 \mathrm{ME}$ & $30.000 \mathrm{KW}$ \\
\cline { 2 - 3 } & $\mathrm{ABC} 40000 \mathrm{ME}$ & $40.000 \mathrm{KW}$ \\
\cline { 2 - 3 } & $\mathrm{ABC} 50000 \mathrm{ME}$ & $50.000 \mathrm{KW}$ \\
\cline { 2 - 3 } & $\mathrm{ABC} 60000 \mathrm{ME}$ & $60.000 \mathrm{KW}$ \\
\hline \multirow{3}{*}{ Big } & $\mathrm{ABC} 70000 \mathrm{BE}$ & $70.000 \mathrm{KW}$ \\
\cline { 2 - 3 } & $\mathrm{ABC} 80000 \mathrm{BE}$ & $80.000 \mathrm{KW}$ \\
\cline { 2 - 3 } & $\mathrm{ABC} 90000 \mathrm{BE}$ & $90.000 \mathrm{KW}$ \\
\cline { 2 - 3 } & $\mathrm{ABC} 100 \mathrm{KBE}$ & $100.000 \mathrm{KW}$ \\
\hline
\end{tabular}

Untuk pengujian evaluasi dan analisa diambilkan data hasil produksi dan quality control pada tahun 2019. Data kemudian produksi kemudian dikelompokan setiap kategori kemudian dilakukan evaluasi dan analisa.

\section{a. Hasil Penghitungan Genset Small Engine}

Tabel 3. Hasil Inpeksi Generator Sets Small Engine periode 2019

\begin{tabular}{|c|c|c|c|c|c|c|c|}
\hline $\begin{array}{l}\overrightarrow{0} \\
\stackrel{0}{0} . \\
\stackrel{0}{0}\end{array}$ & 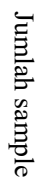 & 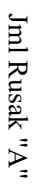 & 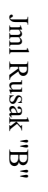 & 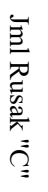 & 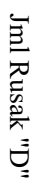 & 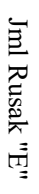 & 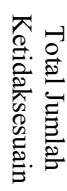 \\
\hline Jan & 40 & 5 & 10 & 7 & 10 & 5 & 37 \\
\hline $\mathrm{Feb}$ & 50 & 4 & 15 & 5 & 10 & 3 & 37 \\
\hline Mar & 40 & 6 & 12 & 3 & 15 & 5 & 41 \\
\hline Apr & 50 & 3 & 5 & 5 & 2 & 1 & 16 \\
\hline Mei & 35 & 5 & 25 & 4 & 15 & 3 & 52 \\
\hline Jun & 35 & 1 & 17 & 8 & 12 & 4 & 42 \\
\hline Jul & 35 & 2 & 15 & 5 & 4 & 2 & 28 \\
\hline Agt & 40 & 7 & 20 & 10 & 4 & 5 & 46 \\
\hline
\end{tabular}

\begin{tabular}{|l|c|c|c|c|c|c|c|} 
Sep & 50 & 6 & 21 & 8 & 8 & 3 & 46 \\
\hline Okt & 60 & 3 & 17 & 5 & 14 & 4 & 43 \\
\hline $\begin{array}{l}\text { No } \\
\text { v }\end{array}$ & 60 & 4 & 14 & 9 & 13 & 4 & 44 \\
\hline Des & 50 & 3 & 12 & 13 & 5 & 6 & 39 \\
\hline
\end{tabular}

Catatan :

1. Periode adalah dari Januari 2019 sampai dengan 2019

2. Jml Rusak A adalah jumlah rusak yang disebabkan karena faktor Kinerja (Perfomance)

3. Jml Rusak B adalah jumlah rusak yang disebabkan karena faktor Estetika (Aesthetic). Karena las yang tidak rapi, pengecetan yang tidak rata, dll

4. Jml Rusak $\mathrm{C}$ adalah jumlah rusak yang disebabkan karena faktor Ketahanan (Realibility).

5. Jml Rusak D adalah jumlah rusak yang disebabkan karena faktor Elektrikal.

6. Jml Rusak E adalah jumlah rusak yang disebabkan karena faktor getaran.

Dengan Excel, kemudian dilakukan penghitugan untuk mencari Cchart dan $U$ chart. Hasil penghitungan $C$-chart adalah adalah seperti tabel 4 dan penggambaran grafik peta kendali yang dihasilkan dapat dilihat pada gambar 2 .

Tabel 4. Hasil Penghitungan $C$-chart dengan Excel Genset Small Engine

\begin{tabular}{|c|c|c|c|c|c|}
\hline 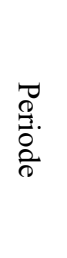 & 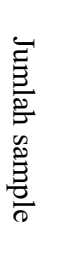 & 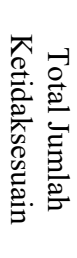 & 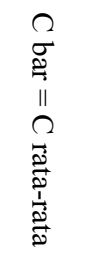 & 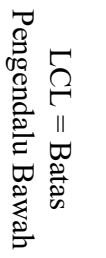 & 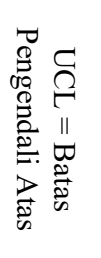 \\
\hline Jan & 40 & 37 & 39,250 & 20,455 & 58,045 \\
\hline Feb & 50 & 37 & 39,250 & 20,455 & 58,045 \\
\hline Mar & 40 & 41 & 39,250 & 20,455 & 58,045 \\
\hline Apr & 50 & 16 & 39,250 & 20,455 & 58,045 \\
\hline Mei & 35 & 52 & 39,250 & 20,455 & 58,045 \\
\hline Jun & 35 & 42 & 39,250 & 20,455 & 58,045 \\
\hline Jul & 35 & 28 & 39,250 & 20,455 & 58,045 \\
\hline Agt & 40 & 46 & 39,250 & 20,455 & 58,045 \\
\hline Sep & 50 & 46 & 39,250 & 20,455 & 58,045 \\
\hline Okt & 60 & 43 & 39,250 & 20,455 & 58,045 \\
\hline Nov & 60 & 44 & 39,250 & 20,455 & 58,045 \\
\hline
\end{tabular}




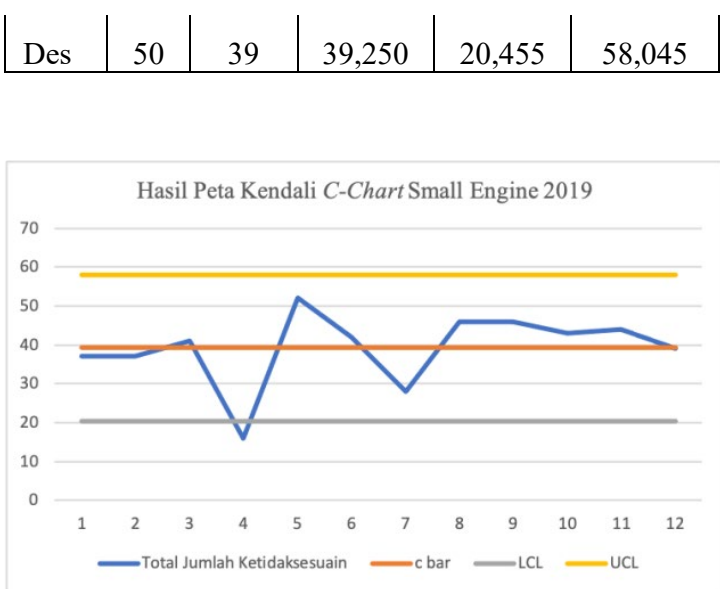

Gambar 2. Hasil Peta Pengendali C-chart Small Engine dengan Excel

Dilakukan juga penghitungan menggunakan minitan agar data yang dihasilkan ada pembanding, sehingga data yang dihasilkan merupakan yang valid.

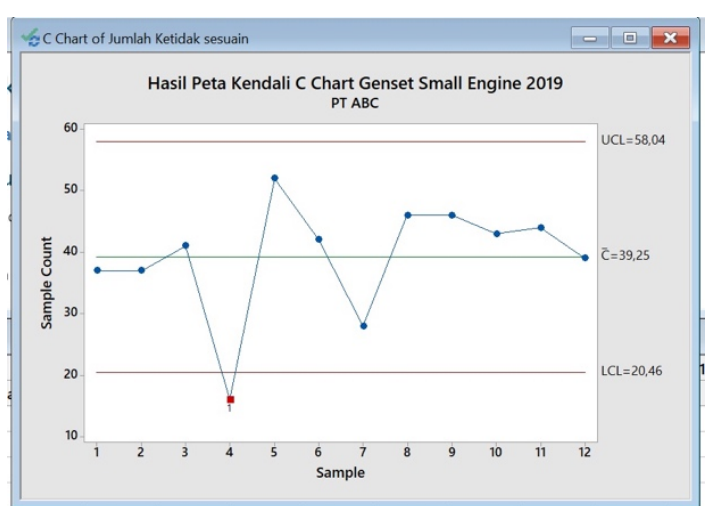

Gambar 3. Hasil Peta Pengendali $C$-chart Small Engine dengan Minitab

Hasil Penghitungan peta kendali $U$-chart mesin genset small engine dengan menggunakan Excel dapat dilihat padat tabel 5 dan gambar 4 sebagai hasil grafik peta kendali $U$-chart small engine

Tabel 5. Hasil Penghitungan U-Chart dengan Excel

\begin{tabular}{|c|c|c|c|c|c|c|}
\hline $\begin{array}{l}\overrightarrow{0} \\
\stackrel{0}{0} . \\
\stackrel{0}{0} \\
\text { م. }\end{array}$ & 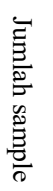 & 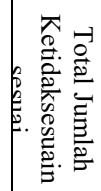 & $\subset$ & 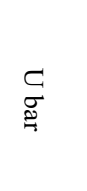 & $\widehat{2}$ & $\stackrel{\overparen{\Omega}}{\rho}$ \\
\hline Jan & 40 & 37 & 0,925 & 0,864 & 0,423 & $\begin{array}{c}1,30 \\
5 \\
\end{array}$ \\
\hline Feb & 50 & 37 & 0,740 & 0,864 & 0,470 & $\begin{array}{c}1,25 \\
9 \\
\end{array}$ \\
\hline
\end{tabular}

\begin{tabular}{|l|c|c|c|c|c|c|} 
Mar & 40 & 41 & 1,025 & 0,864 & 0,423 & $\begin{array}{c}1,30 \\
5\end{array}$ \\
\hline Apr & 50 & 16 & 0,320 & 0,864 & 0,470 & $\begin{array}{c}1,25 \\
9\end{array}$ \\
\hline Mei & 35 & 52 & 1,486 & 0,864 & 0,393 & $\begin{array}{c}1,33 \\
6\end{array}$ \\
\hline Jun & 35 & 42 & 1,200 & 0,864 & 0,393 & $\begin{array}{c}1,33 \\
6\end{array}$ \\
\hline Jul & 35 & 28 & 0,800 & 0,864 & 0,393 & $\begin{array}{c}1,33 \\
6\end{array}$ \\
\hline Agt & 40 & 46 & 1,150 & 0,864 & 0,423 & $\begin{array}{c}1,30 \\
5\end{array}$ \\
\hline Sep & 50 & 46 & 0,920 & 0,864 & 0,470 & $\begin{array}{c}1,25 \\
9\end{array}$ \\
\hline Okt & 60 & 43 & 0,717 & 0,864 & 0,504 & $\begin{array}{c}1,22 \\
4\end{array}$ \\
\hline Nov & 60 & 44 & 0,733 & 0,864 & 0,504 & $\begin{array}{c}1,22 \\
4\end{array}$ \\
\hline Des & 50 & 39 & 0,780 & 0,864 & 0,470 & $\begin{array}{c}1,25 \\
9\end{array}$ \\
\hline
\end{tabular}

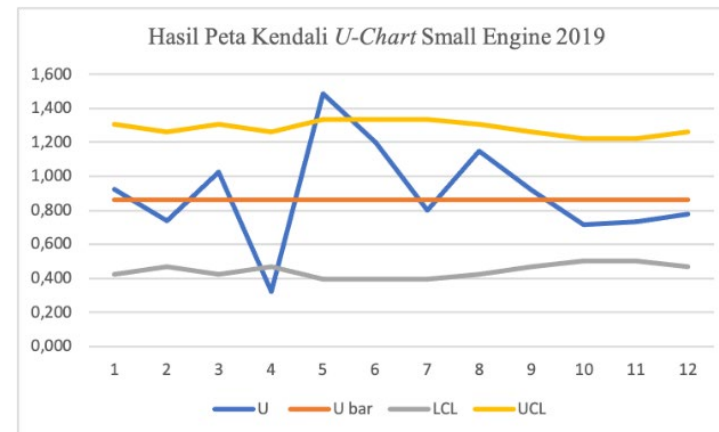

Gambar 4. Hasil Peta Pengendali U-chart Small Engine dengan Excel

Untuk hasil pada program Minitab untuk peta kendali $U$-chart genset Small Engine dapat dihat dibawah ini.

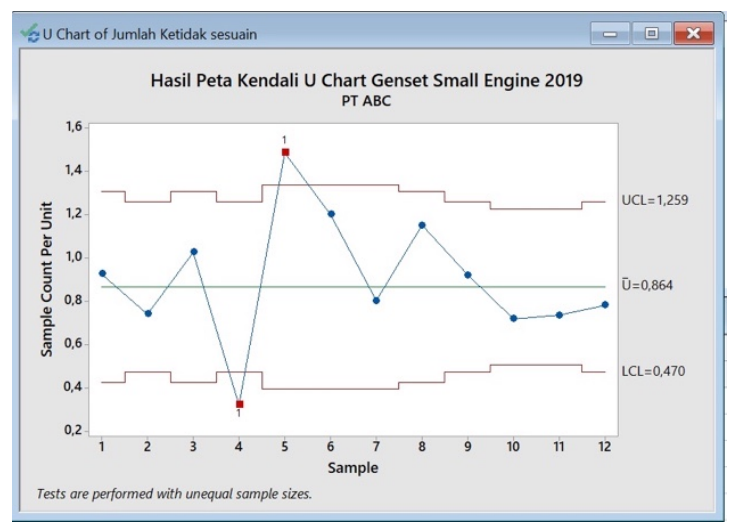

Gambar 5. Hasil Peta Pengendali U-chart Small Engine dengan Minitab 
Dari data yang dihasilkan untuk peta kendali $C$-chart terdapat data yang diluar kendali yaitu pada bulan April 2019, dan untuk peta kendali $U$-chart terdapat produksi yang diluar batas kendali yaitu pada bulan April 2019 dan Mei 2019.

Dapat dilihat bahwa peta kendali $U$-chart dapat mengasilkan data yang lebih akurat dan detail untuk melihat hasil produksi PT ABC. Dengan peta kendali $C$-chart hanya terlihat 1 periode yang luar kendali tetapi peta kendali $U$-Chart memperjelas hasil produksi bulan Mei 2019 juga diluar batas kendali.

Kedua metode ini menggunakan data yang sama, tetapi yang membedakan adalah pengendali $U$-chart meggunakan variabel jumlah sampl sedangkan C-chart tidak menggunakan variabel sample. Variable jumlah sampel yang tidak konstan dipakai dalam perhitungan U-chart sehingga data yang dihasilkan lebih detail.

\section{b. Hasil Penghitungan Genset Medium Engine}

Dilakukan inpeksi pada hasil produksi selama 2019 yang terlah dilakukan sehingga didapatkan hasil inpeksi seperti pada tabel 6 .

Tabel 6. Hasil Inpeksi Generator Sets Medium Engine periode 2019

\begin{tabular}{|c|c|c|c|c|c|c|c|}
\hline 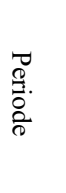 & 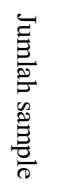 & 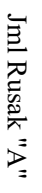 & 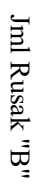 & 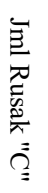 & 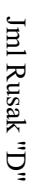 & 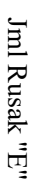 & 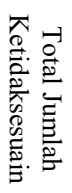 \\
\hline Jan & 30 & 4 & 12 & 5 & 12 & 4 & 37 \\
\hline $\mathrm{Feb}$ & 25 & 3 & 13 & 6 & 9 & 3 & 34 \\
\hline Mar & 30 & 7 & 12 & 4 & 8 & 2 & 33 \\
\hline Apr & 45 & 3 & 6 & 3 & 4 & 2 & 18 \\
\hline Mei & 24 & 4 & 20 & 2 & 4 & 3 & 33 \\
\hline Jun & 33 & 3 & 25 & 1 & 4 & 4 & 37 \\
\hline Jul & 22 & 2 & 12 & 3 & 12 & 5 & 34 \\
\hline Agt & 30 & 5 & 13 & 6 & 5 & 4 & 33 \\
\hline Sep & 44 & 8 & 12 & 9 & 7 & 3 & 39 \\
\hline Okt & 33 & 5 & 10 & 12 & 15 & 5 & 47 \\
\hline Nov & 34 & 2 & 9 & 12 & 10 & 7 & 40 \\
\hline Des & 35 & 2 & 8 & 8 & 5 & 3 & 26 \\
\hline
\end{tabular}

Dilakukan penghitungan untuk mencari peda kendali $C$-chart menggunakan Excel dan Minitab.

Tabel 7. Hasil Penghitungan $C$-chart dengan Excel Genset Medium Engine

\begin{tabular}{|c|c|c|c|c|c|}
\hline $\begin{array}{l}\overrightarrow{0} \\
0 . \\
0 \\
0\end{array}$ & 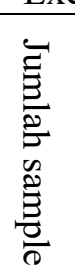 & 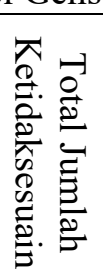 & $\begin{array}{l}\tilde{\mathscr{O}} \\
\mathscr{\Leftrightarrow}\end{array}$ & $\tilde{\Omega}$ & $\stackrel{\Omega}{\Omega}$ \\
\hline Jan & 30 & 37 & 34,25 & 16,69 & 51,81 \\
\hline Feb & 25 & 34 & 34,25 & 16,69 & 51,81 \\
\hline Mar & 30 & 33 & 34,25 & 16,69 & 51,81 \\
\hline Apr & 45 & 18 & 34,25 & 16,69 & 51,81 \\
\hline Mei & 24 & 33 & 34,25 & 16,69 & 51,81 \\
\hline Jun & 33 & 37 & 34,25 & 16,69 & 51,81 \\
\hline Jul & 22 & 34 & 34,25 & 16,69 & 51,81 \\
\hline Agt & 30 & 33 & 34,25 & 16,69 & 51,81 \\
\hline Sep & 44 & 39 & 34,25 & 16,69 & 51,81 \\
\hline Okt & 33 & 47 & 34,25 & 16,69 & 51,81 \\
\hline Nov & 34 & 40 & 34,25 & 16,69 & 51,81 \\
\hline Des & 35 & 26 & 34,25 & 16,69 & 51,81 \\
\hline
\end{tabular}

Hasil dari penghitungan Excel dan Minitab, dapat dibaca pada gambar dibawah ini.

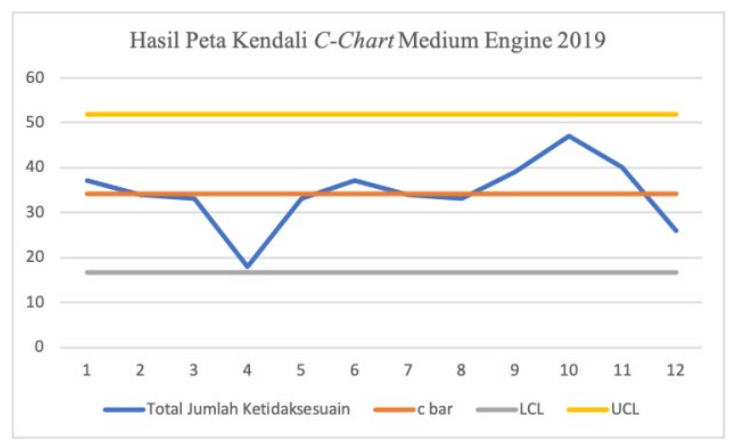

Gambar 6. Hasil Peta Pengendali C-chart Medium Engine dengan Excel 


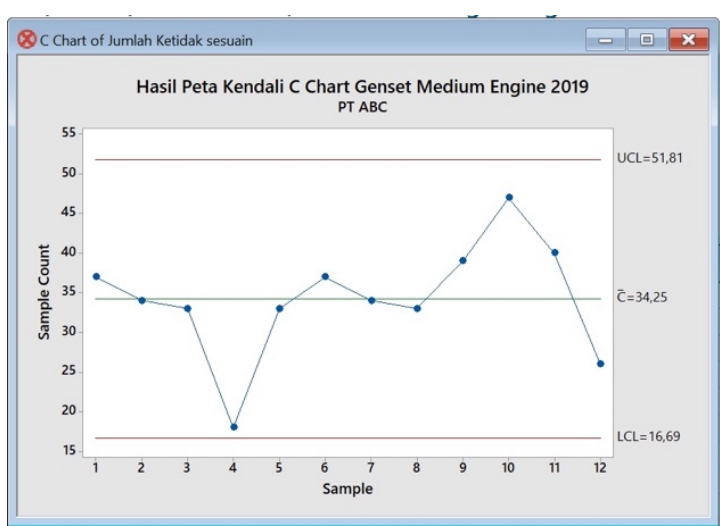

Gambar 7. Hasil Peta Pengendali C-chart Medium Engine dengan Minitab

Dilakukan penghitungan untuk mencari peda kendali $U$-chart menggunakan Excel dan Minitab.

Tabel 8. Hasil Penghitungan $U$-chart dengan Excel Genset Medium Engine

\begin{tabular}{|c|c|c|c|c|c|c|}
\hline 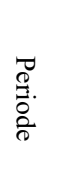 & 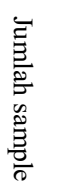 & 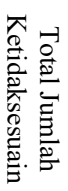 & $\subset$ & $\begin{array}{l}\subset \\
\stackrel{ٌ}{\not}\end{array}$ & $\stackrel{\Gamma}{\Omega}$ & $\stackrel{\overbrace{}}{\Omega}$ \\
\hline Jan & 30 & 37 & 1,233 & 1,068 & 0,502 & 1,633 \\
\hline Feb & 25 & 34 & 1,360 & 1,068 & 0,448 & 1,687 \\
\hline Mar & 30 & 33 & 1,100 & 1,068 & 0,502 & 1,633 \\
\hline Apr & 45 & 18 & 0,400 & 1,068 & 0,605 & 1,530 \\
\hline Mei & 24 & 33 & 1,375 & 1,068 & 0,435 & 1,700 \\
\hline Jun & 33 & 37 & 1,121 & 1,068 & 0,528 & 1,607 \\
\hline Jul & 22 & 34 & 1,545 & 1,068 & 0,407 & 1,728 \\
\hline Agt & 30 & 33 & 1,100 & 1,068 & 0,502 & 1,633 \\
\hline Sep & 44 & 39 & 0,886 & 1,068 & 0,600 & 1,535 \\
\hline Okt & 33 & 47 & 1,424 & 1,068 & 0,528 & 1,607 \\
\hline Nov & 34 & 40 & 1,176 & 1,068 & 0,536 & 1,599 \\
\hline Des & 35 & 26 & 0,743 & 1,068 & 0,544 & 1,591 \\
\hline
\end{tabular}

Hasil dari penghitungan Excel dan Minitab, dapat dibaca pada gambar dibawah ini.

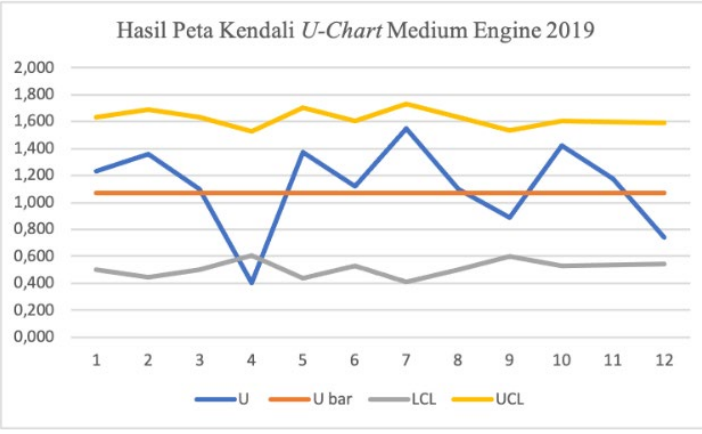

Gambar 8. Hasil Peta Pengendali U-chart Medium Engine dengan Excel

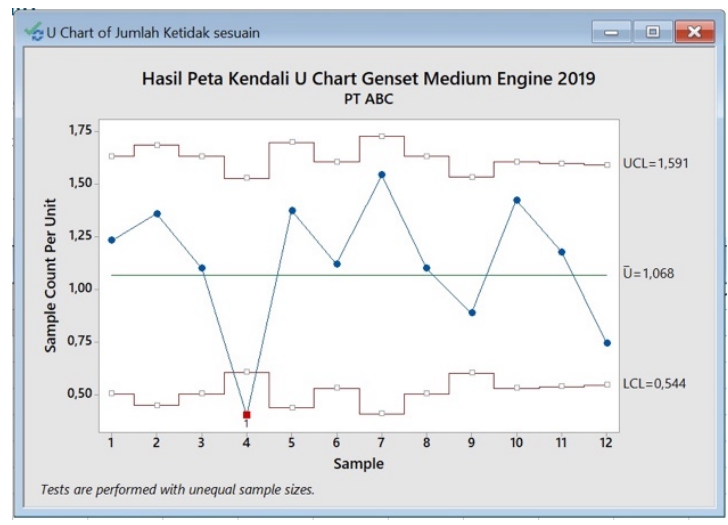

Gambar 9. Hasil Peta Pengendali U-chart Medium Engine dengan Minitab

\section{c. Hasil penghitungan Genset Big Engine}

Inpeksi hasil produksi genset Big Engine disajikan pada tabel 9.

Tabel 9. Hasil Inpeksi Generator Sets Big Engine periode 2019

\begin{tabular}{|c|c|c|c|c|c|c|c|}
\hline $\begin{array}{l}\text { Ð } \\
\stackrel{0}{0} . \\
\text { О. } \\
\text { مे }\end{array}$ & 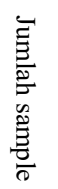 & 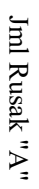 & 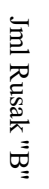 & 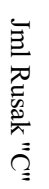 & 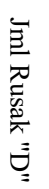 & 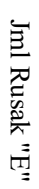 & 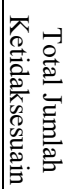 \\
\hline Jan & 20 & 4 & 10 & 4 & 5 & 4 & 27 \\
\hline Feb & 15 & 3 & 11 & 5 & 5 & 3 & 27 \\
\hline Mar & 35 & 2 & 12 & 8 & 12 & 3 & 37 \\
\hline Apr & 23 & 3 & 7 & 3 & 4 & 2 & 19 \\
\hline Mei & 22 & 5 & 8 & 2 & 6 & 1 & 22 \\
\hline Jun & 33 & 4 & 12 & 1 & 7 & 2 & 26 \\
\hline Jul & 21 & 1 & 13 & 5 & 9 & 4 & 32 \\
\hline Agt & 16 & 8 & 15 & 7 & 6 & 3 & 39 \\
\hline Sep & 25 & 3 & 14 & 11 & 4 & 2 & 34 \\
\hline
\end{tabular}




\begin{tabular}{|l|c|c|c|c|c|c|c|} 
Okt & 25 & 2 & 12 & 11 & 3 & 1 & 29 \\
\hline Nov & 16 & 1 & 11 & 4 & 12 & 2 & 30 \\
\hline Des & 24 & 3 & 5 & 5 & 4 & 3 & 20 \\
\hline
\end{tabular}

Dilakukan penghitungan untuk mencari peda kendali $C$-chart menggunakan Excel dan Minitab.

Tabel 10. Hasil Penghitungan $C$-chart dengan Excel Genset Big Engine

\begin{tabular}{|c|c|c|c|c|c|}
\hline $\begin{array}{l}\text { D. } \\
\text { :. } \\
\text { : }\end{array}$ & 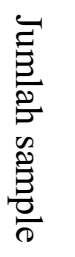 & 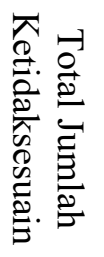 & 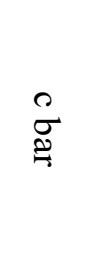 & $\widetilde{\Omega}$ & $\stackrel{\overparen{\Omega}}{\Omega}$ \\
\hline Jan & 20 & 27 & 28,50 & 12,48 & 44,52 \\
\hline Feb & 15 & 27 & 28,50 & 12,48 & 44,52 \\
\hline Mar & 35 & 37 & 28,50 & 12,48 & 44,52 \\
\hline Apr & 23 & 19 & 28,50 & 12,48 & 44,52 \\
\hline Mei & 22 & 22 & 28,50 & 12,48 & 44,52 \\
\hline Jun & 33 & 26 & 28,50 & 12,48 & 44,52 \\
\hline Jul & 21 & 32 & 28,50 & 12,48 & 44,52 \\
\hline Agt & 16 & 39 & 28,50 & 12,48 & 44,52 \\
\hline Sep & 25 & 34 & 28,50 & 12,48 & 44,52 \\
\hline Okt & 25 & 29 & 28,50 & 12,48 & 44,52 \\
\hline Nov & 16 & 30 & 28,50 & 12,48 & 44,52 \\
\hline Des & 24 & 20 & 28,50 & 12,48 & 44,52 \\
\hline
\end{tabular}

Hasil dari penghitungan Excel dan Minitab, dapat dibaca pada gambar 9 dan 10.

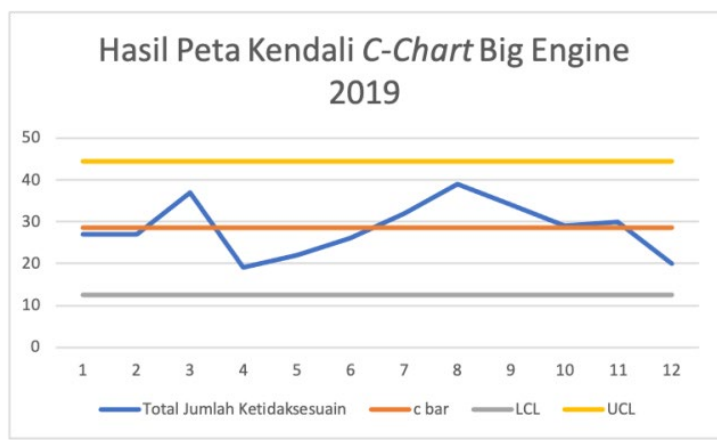

Gambar 10. Hasil Peta Pengendali C-chart Big Engine dengan Excel

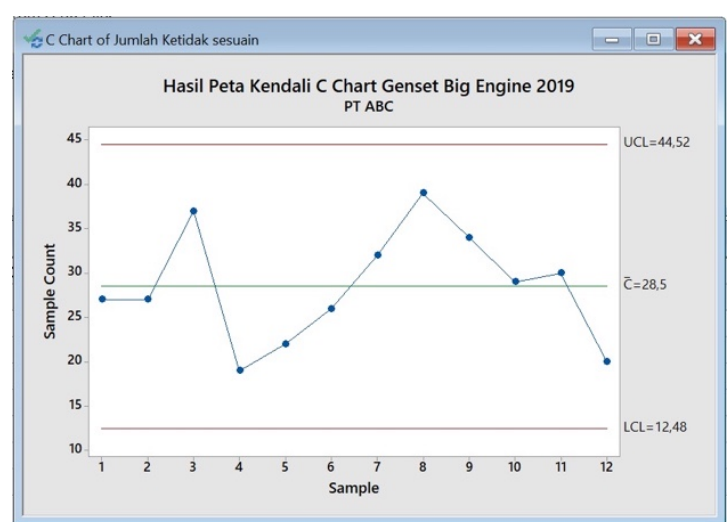

Gambar 11. Hasil Peta Pengendali $C$ chart Big Engine dengan Minitab

Dilakukan penghitungan untuk mencari peda kendali U-Chart menggunakan Excel dan Minitab.

Tabel 11. Hasil Penghitungan $U$-chart dengan Excel Genset Big Engine

\begin{tabular}{|c|c|c|c|c|c|c|}
\hline $\begin{array}{l}\overrightarrow{0} \\
\stackrel{0}{0} . \\
\stackrel{0}{0}\end{array}$ & 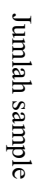 & 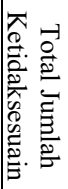 & $\subset$ & $\begin{array}{l}\underset{ }{\stackrel{2}{*}} \\
\stackrel{\Rightarrow}{*}\end{array}$ & $\widehat{2}$ & $\stackrel{\mathcal{\Omega}}{\Omega}$ \\
\hline Jan & 20 & 27 & 1,350 & 1,244 & 0,496 & 1,992 \\
\hline Feb & 15 & 27 & 1,800 & 1,244 & 0,380 & 2,107 \\
\hline Mar & 35 & 37 & 1,057 & 1,244 & 0,678 & 1,809 \\
\hline Apr & 23 & 19 & 0,826 & 1,244 & 0,546 & 1,941 \\
\hline Mei & 22 & 22 & 1,000 & 1,244 & 0,530 & 1,957 \\
\hline Jun & 33 & 26 & 0,788 & 1,244 & 0,661 & 1,826 \\
\hline $\mathrm{Jul}$ & 21 & 32 & 1,524 & 1,244 & 0,514 & 1,974 \\
\hline Agt & 16 & 39 & 2,438 & 1,244 & 0,407 & 2,080 \\
\hline Sep & 25 & 34 & 1,360 & 1,244 & 0,575 & 1,913 \\
\hline Okt & 25 & 29 & 1,160 & 1,244 & 0,575 & 1,913 \\
\hline Nov & 16 & 30 & 1,875 & 1,244 & 0,407 & 2,080 \\
\hline Des & 24 & 20 & 0,833 & 1,244 & 0,561 & 1,927 \\
\hline
\end{tabular}


Hasil dari penghitungan Excel dan Minitab, dapat dibaca pada gambar dibawah ini.

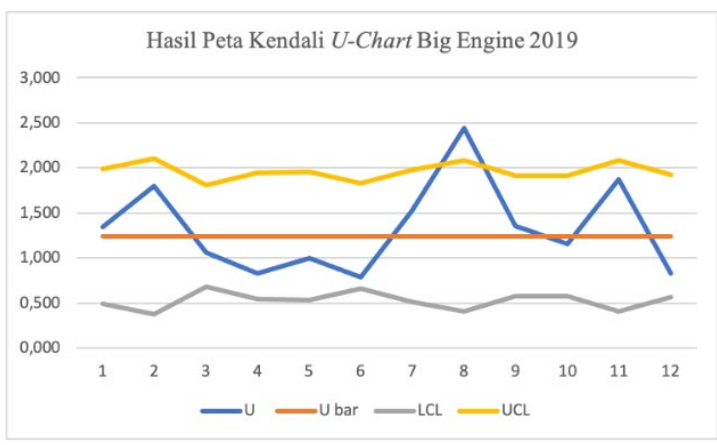

Gambar 11. Hasil Peta Pengendali U-chart Big Engine dengan Excel

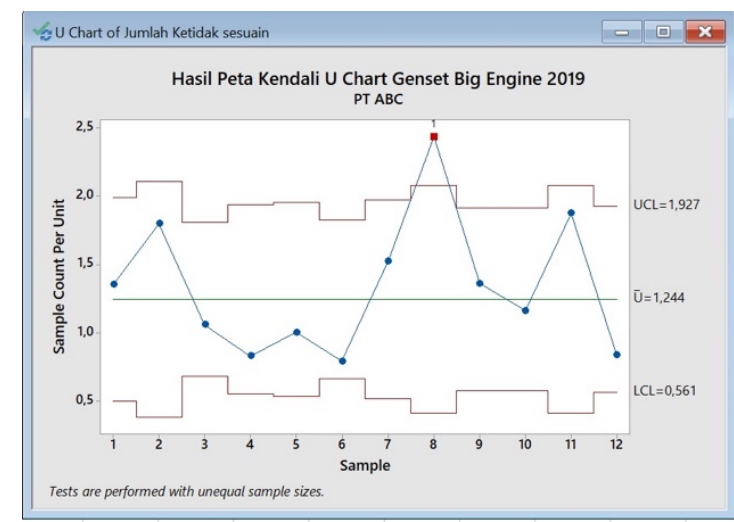

Gambar 12. Hasil Peta Pengendali U-chart

Big Engine dengan Minitab

\section{KESIMPULAN DAN SARAN}

\section{a. Kesimpulan}

Kesimpulan dari penelitian ini adalah:

1) Produksi genset disemua kategori terjadi di luar di luar kendali walapun dengan menggunakan metode $C$-chart untuk kategori medium engine dan big engine masih dalam kendali.

2) Peta kendali $U$-chart dapat memberikan informasi yang lebih akurat dan detail dalam menganaslisa hasil produksi (Quality Control).

3) Diperlukan evaluasi lebih lanjut mengenai segala sesuatu yang berhubungan dengan produksi genset terutama tenaga kerja. Selain itu, evaluasi pda peralatan kerja, bahan baku juga juga perlu dilakukan..

\section{b. Saran}

Saran untuk penulisan ini adalah:

1) Dilakukan penghitungan / evaluasi untuk setiap tipe produksi genset dengan metode $U$-chart sehingga didapatkan informasi mengenai tipe genset yang hasil kendali mutunya diluar batas kendali, sehingga dapat dilakukan evaluasi lebih lanjut.

\section{REFERENSI}

Dorothea W. A. 2010. Pengendalian kualitas statistik (pendekatan kuatitatif dalam manajemen kualitas). Yokyakarta: Andi.

Gasper, Vincent. 2005. Total Quality Manajement. Jakarta: Gramedia Pustaka Utama.

Gasper, Vincent. 2003. Metode Analisis untuk Peningkatan Kualitas. Jakarta: Gramedia Pustaka Utama.

Sinola yang berjudul "Analisis Pengendalian Kualitas Produksi Air Minum Dalam Kemasan (AMDK dengan Menggunakan peta kendali C Dan peta kendali U (Study Kasus di PT. Sariguna Primatirta Makassar).", Skripsi Jurusan Matematika Fakultas Sains dan Teknologi. UIN Alauddin Makassar. 2012

Ola Yemima1, Darnah A. Nohe, Yuki Novia Nasution yang berjudul "Penerapan Peta Kendali Demerit dan Diagram Pareto Pada Pengontrolan Kualitas Produksi (Studi Kasus: Produksi Botol Sosro di PT. $X$ Surabaya)" Jurnal EKSPONENSIAL Volume 5 Nomor 2, Nopember 2014 ISSN 2085-7829

Didiharyono yang berjudul "Penerapan Metode Statistical Processing Control Untuk Menganalisis Pengendalian Kualitas Produk pada PT. Asera Tirta Posidonia, Kota Palopo" Jurnal Equilibrium Volume 2 Nomor 4, Desember 2016 ISSN: 2460-7150

https://sinta.unud.ac.id/uploads/dokumen dir/ a122eebb367a032a441c26d607b74176.p df

$\underline{h t t p: / / e-}$

journal.uajy.ac.id/2721/3/2EA14772.pdf https://eriskusnadi.com/2012/06/09/statisticalprocess-control/

https://www.minitab.com/en-us/ 